\title{
National cataract surgery survey 1997-8: a report of the results of the clinical outcomes
}

\author{
Parul Desai, D C Minassian, Angela Reidy
}

\begin{abstract}
Aims-A national survey of over 100 hospitals in the UK was carried out to collect routine clinical information on the outcomes of cataract surgery. The clinical outcomes of interest were: visual acuity at time of discharge from postoperative hospital follow up, visual acuity at time of final refraction; complications related to surgery occurring during the operation, within 48 hours of surgery, and within 3 months of surgery. In addition, information on age and comorbidity was obtained. This article reports on the findings of the experience of approximately 18000 patients who had cataract surgery in the hospital eye service of the NHS. Results-Of those with no ocular comorbidity, $85 \%$ achieved a visual acuity of $6 / 12$ or better on discharge from postoperative hospital follow up, while $65 \%$ of patients with a serious co-existing eye disease achieved this level of acuity at this time. At final refraction, $\mathbf{9 2 \%}$ of patients without ocular comorbidity and $77 \%$ of patients with ocular comorbidity achieved $6 / 12$ or better visual acuity. The following main risk indicators were associated with visual outcomes and complications related to surgery: age, other eye diseases, diabetes and stroke, type of surgical procedure, and grade of surgeon.

Conclusions-The acceptability of these findings could fruitfully be the subject of discussion within the ophthalmic community and hopefully issues arising out of the study can lead to research, especially in-depth studies of the outcomes of cataract surgery in those patients with coexisting serious eye conditions.

(Br F Ophthalmol 1999;83:1336-1340)
\end{abstract}

Moorfields Eye

Hospital, London EC1V 2PD

P Desai

A Reidy

Institute of Ophthalmology, University College

London, London

EC1V 9EL

D C Minassian

Correspondence to: Miss Desai

Accepted for publication 28 July 1999
By the next millennium we may reach 200000 as the annual number of cataract operations performed within the NHS. The need for a programme of research into the outcomes of this common surgical procedure has been recognised for some time. ${ }^{1}$ This recently completed study had as its objective the provision of baseline information on patient profiling ${ }^{2}$ and the application of epidemiological method to specifically collected, large scale, routine clinical information on the outcomes of cataract surgery. Within this study particular attention was paid to age, comorbidity, visual acuity, and complications of surgery. This article reports on the findings of the experience of approximately 18000 patients who had cata- ract surgery in the hospital eye service of the National Health Service (NHS).

\section{Method}

As described elsewhere ${ }^{2}$ and summarised here, more than 100 unselected hospital eye units within the UK agreed to collect data on patients undergoing cataract surgery according to a predefined set of preoperative and postoperative forms. Data were collected on patients undergoing cataract extraction between September and December of 1997 and for a period up to 3 months after surgery. Preoperative data were collected prospectively and postoperative data were collected both prospectively and retrospectively.

The data collection forms were developed by a team that included ophthalmologists and epidemiologists. A handbook of instructions for data collection and recording was prepared to complement the standardised forms. This was to help ensure a standard method of data extraction and recording. The forms were tested through pilot studies. The work in each unit was carried out under the auspices of the ophthalmic clinical director. The recording of data was devolved to varying degrees to clinical audit staff and community optometrists were requested to return information on visual acuity on patients who presented within 3 months of surgery.

The clinical outcomes of interest were Snellen visual acuity after surgery (with correction if worn, or with pinhole) and complications related to surgery.

Visual outcomes for cataract surgery are reported as the achievement of a defined level of Snellen acuity (6/12 or better in the surgery eye) at two points in time during the postoperative recovery process: at time of discharge from follow up in hospital and at final refraction performed within 3 months of surgery. These represent key stages in patients' postoperative clinical recovery. In addition, at final refraction when recovery is expected to have stabilised, a more stringent visual outcome of achieving Snellen acuity of 6/9 or better (in the operated eye) is also reported.

The complications of surgery of interest were those clinically evident events which occurred during the operation, within 48 hours of surgery, or within 3 months of surgery. Having noted from a survey of practice the shorter postoperative follow up periods in eye clinics, ${ }^{3}$ the complications considered within 3 months of surgery were only those which were sight threatening events necessitating a hospital clinical assessment and further management. These were clinically evident endophthalmitis 
Table 1 Variables included in analyses for risk indicators of poor clinical outcome

\begin{tabular}{|c|c|}
\hline Variables and their categories & \\
\hline Age (years) & \\
\hline 50 to 59 & referent group \\
\hline 60 to 69 & \\
\hline 70 to 79 & \\
\hline 80 to 89 & \\
\hline 90 and over & \\
\hline Sex & \\
\hline $\begin{array}{l}\text { male } \\
\text { female }\end{array}$ & referent group \\
\hline Ocular comorbidity ${ }^{\star}$ & \\
\hline $\begin{array}{l}\text { absent } \\
\text { present }\end{array}$ & referent group \\
\hline Diabetes mellitus & \\
\hline $\begin{array}{l}\text { absent } \\
\text { present }\end{array}$ & referent group \\
\hline Stroke & \\
\hline $\begin{array}{l}\text { absent } \\
\text { present }\end{array}$ & referent group \\
\hline Surgical procedure & \\
\hline Phacoemulsification & referent group \\
\hline Extracapsular extraction & \\
\hline Grade of surgeon & \\
\hline Consultant & referent group \\
\hline Specialist registrar & \\
\hline Senior house officer & \\
\hline Associate specialist & \\
\hline Other & \\
\hline $\begin{array}{l}\text { "Capsule rupture and vitreous loss } \\
\text { during the operation" } \dagger\end{array}$ & \\
\hline absent & referent group \\
\hline present & \\
\hline
\end{tabular}

^Includes age related macular degeneration, glaucoma, diabetic retinopathy, amblyopia.

tOnly included in analysis for endophthalmitis and retinal detachment/tear.

and retinal detachment or retinal tear. No differentiation was made between sterile and culture proved endophthalmitis.

A specially designed computer database application was used for entry, validation, and preparation of the data for analysis and the sPss software was used for data analysis. Multiple logistic regression analysis was employed to identify risk indicators for the following poor clinical outcomes: visual outcome at discharge from postoperative hospital follow up; surgically related complications occurring within 48 hours of surgery; endophthalmitis within 3 months of surgery; retinal detachment or tear within 3 months of surgery. The candidate variables (potential risk indicators, confounders, and effect modifiers) used in the analyses are shown in Table 1. Before multiple logistic regression, a comprehensive set of analyses were performed to assess crude odds ratios for each variable without adjustment for confounding, followed by stratified data analysis to identify major effect modification and/or confounding. Detailed cross tabulations were made to explore interrelations between the potential risk indicators, and in particular, to identify extreme correlation. The strategy used for the multiple logistic regression was based on the methods described by Kleinbaum et al. ${ }^{4}$ The main findings from the regression analysis are reported, and estimates for the risk of a poor outcome (presented as odds ratios) are provided having adjusted for the effect of all other variables in the regression models.

\section{Results}

Data on 18454 patients of 50 years of age and more were available for analysis; $77 \%$ of these patients had surgery performed by phacoemul-
Table 2 Availability of follow up data within 3 months of surgery

\begin{tabular}{|c|c|c|}
\hline & \multicolumn{2}{|c|}{$\begin{array}{l}\text { Follow up data within } 3 \text { months of } \\
\text { surgery }\end{array}$} \\
\hline & Not available (\%) & Available (\%) \\
\hline \multicolumn{3}{|c|}{ (A) Patient characteristics: } \\
\hline \multicolumn{3}{|l|}{1 Age group } \\
\hline $50-54$ & $64(2)$ & $307(2)$ \\
\hline $55-59$ & $104(4)$ & $570(4)$ \\
\hline $60-64$ & $155(6)$ & $914(6)$ \\
\hline $65-69$ & $282(10)$ & $1591(10)$ \\
\hline $70-74$ & $414(15)$ & $2579(16)$ \\
\hline $75-79$ & $555(21)$ & $3595(23)$ \\
\hline $80-84$ & $578(22)$ & $3256(21)$ \\
\hline $85+$ & $526(20)$ & $2964(19)$ \\
\hline \multicolumn{3}{|l|}{2 Sex } \\
\hline Female & $1735(65)$ & $10303(65)$ \\
\hline Male & $943(35)$ & $5473(35)$ \\
\hline \multicolumn{3}{|c|}{3 Visual acuity on admission } \\
\hline $6 / 6$ to $6 / 12$ & $478(22)$ & $3851(28)$ \\
\hline $6 / 18$ to $6 / 60$ & $1169(55)$ & $7110(51)$ \\
\hline less than $6 / 60$ & $483(23)$ & $2941(21)$ \\
\hline \multicolumn{3}{|l|}{4 Ocular comorbidity } \\
\hline Absent & $1967(73)$ & $11328(72)$ \\
\hline Present & $711(27)$ & $4448(28)$ \\
\hline \multicolumn{3}{|l|}{5 Diabetes mellitus } \\
\hline Absent & $2361(88)$ & $14031(89)$ \\
\hline Present & $317(12)$ & $1745(11)$ \\
\hline \multicolumn{3}{|l|}{6 History of stroke } \\
\hline Yes & $2581(96)$ & $15029(95)$ \\
\hline No & $97(4)$ & $747(5)$ \\
\hline \multicolumn{3}{|c|}{ (B) Surgery characteristics: } \\
\hline Phacoemulsification & $2097(80)$ & $12013(77)$ \\
\hline ECCE & $507(20)$ & $3688(23)$ \\
\hline \multicolumn{3}{|l|}{2 Grade of surgeon } \\
\hline Consultant & $1509(57)$ & $10131(64)$ \\
\hline Specialist registrar & $509(19)$ & $2415(15)$ \\
\hline Senior house officer & $199(8)$ & $971(6)$ \\
\hline Associate specialist & $123(5)$ & $1116(7)$ \\
\hline Other & $293(11)$ & $1087(7)$ \\
\hline \multicolumn{3}{|l|}{$\begin{array}{l}3 \text { "Capsule rupture and } \\
\text { vitreous loss" }\end{array}$} \\
\hline Absent & $2556(95)$ & $15081(96)$ \\
\hline Present & $122(5)$ & $695(4)$ \\
\hline
\end{tabular}

sification. Follow up data within 3 months of surgery were available for 15787 patients. As shown in Table 2, there were no important differences between patients with and without follow up data within 3 months of surgery in terms of the patient and surgery characteristics that were used in the subsequent data analysis and regression models.

Visual acuity data before and after surgery were available for 14528 patients. Of these patients $8526(58.7 \%)$ had no ocular comorbidity (age related macular degeneration, glaucoma, diabetic retinopathy, amblyopia). Information on 8872 patients was available at time of final refraction, and of these $5312(59.9 \%)$ were free from other serious eye conditions.

\section{VISUAL ACUITY OUTCOME}

At time of discharge from postoperative hospital follow up

Seventy seven per cent of all patients achieved visual acuity of $6 / 12$ or better, $20 \%$ achieved a visual acuity of $6 / 18$ to $6 / 60$, and $3 \%$ had a visual outcome of less than $6 / 60$ at this time (Table 3).

Eighty five per cent of patients with no ocular comorbidity achieved a visual acuity of $6 / 12$ or better, while $65 \%$ of patients with ocular comorbidity achieved this level of visual outcome at discharge from hospital follow up (Table 4). 
Table 3 Visual acuity outcome by age: at discharge from postoperative hospital follow up

\begin{tabular}{lrrr}
\hline \multirow{4}{*}{$\begin{array}{l}\text { Age group } \\
\text { (years) }\end{array}$} & \multicolumn{4}{l}{ Visual acuity $($ row $(\%))$} \\
\cline { 2 - 4 } & $6 / 12$ or better & \multicolumn{1}{l}{$6 / 18$ to $6 / 60$} & less than 6/60 \\
\hline $50-54$ & $239(84)$ & $38(13)$ & $8(3)$ \\
$55-59$ & $449(85)$ & $64(12)$ & $14(3)$ \\
$60-64$ & $696(83)$ & $123(15)$ & $15(2)$ \\
$65-69$ & $1193(83)$ & $220(15)$ & $30(2)$ \\
$70-74$ & $1943(82)$ & $371(16)$ & $50(2)$ \\
$75-79$ & $2672(81)$ & $584(17)$ & $61(2)$ \\
$80-84$ & $2207(73)$ & $668(22)$ & $135(5)$ \\
$85-89$ & $1361(67)$ & $548(27)$ & $126(6)$ \\
$90+$ & $383(54)$ & $258(36)$ & $72(10)$ \\
All ages & $11143(77)$ & $2874(20)$ & $511(3)$ \\
\hline
\end{tabular}

Number of patients with incomplete data (excluded from this table) $=1259$.

Age was related to the level of visual acuity achieved after surgery, younger patients having better outcomes (Table 3).

\section{At time of final refraction}

Eighty six per cent $(85.7 \%)$ of all patients achieved a visual acuity of $6 / 12$ or better at this time; $12 \%$ of patients achieved acuity of $6 / 18$ to $6 / 60$, and $2 \%$ had a visual outcome of less than $6 / 60$ at final refraction.

Ninety two per cent $(91.7 \%)$ of patients with no ocular comorbidity achieved $6 / 12$ or better acuity at final refraction compared which $77 \%$ of patients with ocular comorbidity (Table 5).

Using a more stringent level of visual acuity outcome of $6 / 9$ or better at this time, then $73 \%$ of all patients achieved this level of visual acu-

Table 4 Visual acuity outcome by ocular comorbidity: at discharge from postoperative hospital follow up

\begin{tabular}{|c|c|c|c|c|}
\hline \multirow[b]{2}{*}{ Ocular comorbidity } & \multicolumn{4}{|c|}{ Visual acuity (row (\%)) } \\
\hline & $6 / 12$ or better & $6 / 18$ to $6 / 60$ & less than $6 / 60$ & Total \\
\hline \multicolumn{5}{|c|}{ Age related macular disease } \\
\hline present & $1525(59)$ & $799(31)$ & $253(10)$ & 2577 \\
\hline absent & $9618(81)$ & $2075(17)$ & $258(2)$ & 11951 \\
\hline \multicolumn{5}{|l|}{ Glaucoma } \\
\hline present & $1125(67)$ & $434(26)$ & $129(7)$ & 1688 \\
\hline absent & $10018(78)$ & $2440(19)$ & $382(3)$ & 12840 \\
\hline \multicolumn{5}{|l|}{ Diabetic retinopathy } \\
\hline present & $264(56)$ & $172(36)$ & $40(8)$ & 476 \\
\hline absent & $10879(78)$ & $2702(19)$ & 471 (3) & 14052 \\
\hline \multicolumn{5}{|l|}{ Amblyopia } \\
\hline present & $104(50)$ & $86(42)$ & $16(8)$ & 206 \\
\hline absent & $11039(77)$ & $2788(20)$ & $495(3)$ & 14322 \\
\hline \multicolumn{5}{|c|}{ Any ocular comorbidity } \\
\hline present & $3902(65)$ & $1675(28)$ & $425(7)$ & 6002 \\
\hline absent & $7241(85)$ & $1199(14)$ & $86(1)$ & 8526 \\
\hline
\end{tabular}

Number of patients with incomplete data (excluded from the table) $=1259$.

Table 5 Visual acuity outcome by ocular comorbidity: at final refraction

\begin{tabular}{|c|c|c|c|c|}
\hline \multirow[b]{2}{*}{ Ocular comorbidity } & \multicolumn{4}{|c|}{ Visual acuity (row (\%)) } \\
\hline & $6 / 12$ or better & $6 / 18$ to $6 / 60$ & less than $6 / 60$ & Total \\
\hline \multicolumn{5}{|c|}{ Age related macular disease } \\
\hline present & $1138(72)$ & $344(22)$ & $93(6)$ & 1575 \\
\hline absent & $6462(89)$ & $751(10)$ & $84(1)$ & 7297 \\
\hline \multicolumn{5}{|l|}{ Glaucoma } \\
\hline present & $717(77)$ & $178(19)$ & $32(4)$ & 927 \\
\hline absent & $6883(87)$ & $917(11)$ & $145(2)$ & 7945 \\
\hline \multicolumn{5}{|l|}{ Diabetic retinopathy } \\
\hline present & $179(68)$ & $74(28)$ & $12(4)$ & 265 \\
\hline absent & $7421(86)$ & $1021(12)$ & $165(2)$ & 8607 \\
\hline \multicolumn{5}{|l|}{ Amblyopia } \\
\hline present & $88(67)$ & $38(29)$ & $5(4)$ & 131 \\
\hline absent & $7512(86)$ & $1057(12)$ & $172(2)$ & 8741 \\
\hline \multicolumn{5}{|c|}{ Any ocular comorbidity } \\
\hline present & $2731(77)$ & $686(19)$ & $143(4)$ & 3560 \\
\hline absent & $4869(92)$ & $409(7)$ & $34(1)$ & 8526 \\
\hline
\end{tabular}

Number of patients with incomplete data (excluded from the table) $=3701$. ity. Seventy six per cent of patients having a phacoemulsification procedure achieved $6 / 9$ or better visual acuity, while $63 \%$ of patients having an extracapsular cataract extraction (ECCE) achieved this level of acuity at final refraction.

Eighty per cent of all patients without ocular comorbidity achieved $6 / 9$ or better at final refraction. Of this group of patients without ocular comorbidity, $82 \%$ of patients having a phacoemulsification procedure achieved this level of visual acuity while $72 \%$ of patients having an ECCE procedure achieved this $6 / 9$ or better acuity at final refraction. Similarly, $61 \%$ of all patients with ocular comorbidity achieved $6 / 9$ or better visual acuity at final refraction. Of this group, $65 \%$ of patients having a phacoemulsification procedure achieved this level of acuity and $47 \%$ of patients having an ECCE procedure achieved 6/9 or better visual acuity at final refraction.

\section{Visual outcome by specific comorbid ocular} conditions

Visual outcomes in patients with specific comorbid ocular conditions are presented in Tables 4 and 5. At discharge from postoperative hospital follow up a visual acuity of $6 / 12$ or better was achieved in 67\% (1125/1688) of patients with glaucoma, in $59 \%(1525 / 2577)$ of patients with age related macular disease, in $56 \%(264 / 476)$ of patients with diabetic retinopathy and in half $(50 \%, 104 / 206)$ of the patients with amblyopia (Table 4).

At time of final refraction, the proportion of patients achieving a good visual outcome were higher for each of these comorbid conditions (Table 5). Seventy seven per cent of patients with glaucoma (717/927) and 72\% (1138/ 1575 ) of patients with age related macular disease achieved visual acuity of $6 / 12$ or better at this time. About two thirds of patients with diabetic retinopathy $(68 \%, 179 / 265)$ and amblyopia $(67 \%, 88 / 131)$ had a good visual outcome at final refraction.

Risk indicators for poor visual outcome (less than 6/12) at discharge from postoperative hospital follow up - main findings

The results of the multiple logistic regression analysis showed that older age was associated with higher risk, the oldest age group (90 years and over) having four times higher risk of poor visual outcome at this time compared with the youngest group (50-59 years). The 95\% confidence limits for this odds ratio were 3.1 to 5.1 .

The presence of ocular comorbidity was also associated with a higher risk (odds ratio 2.7, 95\% CI 2.5 to 2.9 ).

Patients with diabetes mellitus or stroke were less likely to achieve a "good" outcome having odds ratios of 1.6 (95\% CI 1.4 to 1.8 ) and 1.3 (95\% CI 1.1 to 1.6$)$ respectively.

Patients having an ECCE were twice as likely to fail to achieve $6 / 12$ or better at time of discharge from hospital follow up (odds ratio phacoemulsification $/ \mathrm{ECCE}=0.5,95 \%$ CI 0.4 to 0.5 ) 
Table 6 Events occurring during surgery ( $n=18472$ patients)

\begin{tabular}{lc}
\hline Event & $\begin{array}{l}\text { Frequency } \\
\text { No (\%) }\end{array}$ \\
\hline Anterior chamber haemorrhage & $85(0.5)$ \\
Anterior chamber collapse & $98(0.5)$ \\
Torn iris & $76(0.4)$ \\
Iris emulsification & $63(0.3)$ \\
Persistent iris prolapse & $136(0.07)$ \\
Choroidal haemorrhage & $13(0.1)$ \\
Capsule rupture and vitreous loss & $818(4.4)$ \\
Incomplete cortical clean up & $192(1.0)$ \\
Loss of nuclear fragment into vitreous & $51(0.3)$ \\
Loss of intraocular lens into vitreous & $11(0.16)$ \\
Torn Descemet's membrane & $21(0.1)$ \\
Abnormality in wound closure & $26(0.1)$ \\
Any of the above events & $1388(7.5)$ \\
\hline
\end{tabular}

Table 7 Events occurring within 48 hours of surgery ( $n=17257$ patients)

\begin{tabular}{|c|c|}
\hline Event & $\begin{array}{l}\text { Frequency } \\
\text { No }(\%)\end{array}$ \\
\hline Raised intraocular pressure & $1356(7.9)$ \\
\hline Periocular bruising more than expected & $173(1)$ \\
\hline Periocular oedema more than expected & $76(0.4)$ \\
\hline External eye infection & $11(0.06)$ \\
\hline Wound leak/rupture & $212(1.2)$ \\
\hline Vitreous to section & $52(0.3)$ \\
\hline Corneal oedema & $1646(9.5)$ \\
\hline Hyphaema & $195(1.1)$ \\
\hline Hypopoyon & $3(0.02)$ \\
\hline Uveitis & $972(5.6)$ \\
\hline Iris abnormality & $158(0.9)$ \\
\hline Pupil block & $5(0.03)$ \\
\hline Capsule opacity & $64(0.4)$ \\
\hline Retained lens material & $196(1.1)$ \\
\hline Intraocular lens dislocation & $25(0.1)$ \\
\hline Cystoid macular oedema & $8(0.05)$ \\
\hline Retinal tear & $4(0.02)$ \\
\hline Retinal detachment & $6(0.03)$ \\
\hline Choroiditis & $1(0.006)$ \\
\hline Optic neuropathy & $1(0.006)$ \\
\hline Endophthalmitis & $5(0.03)$ \\
\hline Any of the above & $4021(23.3)$ \\
\hline
\end{tabular}

COMPLICATIONS RELATED TO SURGERY

Events occurring during the operation

Overall, $7.5 \%$ of patients experienced one or more of the range of events shown in Table 6 . The most frequently occurring event was capsule rupture and vitreous loss which occurred in $4.4 \%$ of patients. There was no appreciable difference observed by type of surgical procedure $(4.3 \%$ for phacoemulsification and $4.8 \%$ for $\mathrm{ECCE})$.

Events occurring within 48 hours of surgery

During this early postoperative period $23.3 \%$ of all patients had one or more of the complications presented in Table 7. These ranged from minor to potentially sight threatening events. The most frequently recorded events were corneal oedema $(9.5 \%)$, raised intraocular pressure $(7.9 \%)$, and uveitis $(5.6 \%)$. These occurred with similar frequency for both phacoemulsification and extracapsular extraction.

Risk indicators for complications within 48 hours of surgery - main findings

A trend of increasing risk with age was observed, the oldest age group (90 years and over) having 1.6 times the risk of a complication within this early postoperative period compared with the youngest group (50-59 years). The presence of ocular comorbidity was significantly associated with a surgically related complication at this time having an odds ratio 1.2 (95\% CI 1.1 to 1.3$)$. Having the operation performed by a surgeon in the senior house officer grade was also associated with higher frequency of complications (compared with consultant grade) in this postoperative period (odds ratio $1.6,95 \%$ CI 1.4 to 1.8 ).

\section{WITHIN 3 MONTHS OF SURGERY}

In the 15787 patients for whom follow up data were available there were 26 cases of endophthalmitis within 3 months of surgery $(0.1 \%$, $95 \%$ CI $0.1 \%$ to $0.2 \%$ ). At discharge from hospital follow up, over half (54\%) of these patients achieved a visual acuity of $6 / 12$ or better, $27 \%$ of patients had visual acuity of $6 / 18$ to $6 / 60$, and $19 \%$ of patients had acuity less than $6 / 60$.

There were 26/15787 cases of retinal detachment or tear within 3 months of cataract extraction $(0.1 \%, 95 \%$ CI $0.1 \%$ to $0.2 \%)$. By the time of discharge from hospital follow up, $30.5 \%$ of these patients achieved a visual acuity of $6 / 12$ or better, $30.5 \%$ achieved $6 / 18$ to $6 / 60$, and the $39 \%$ of patients had less than $6 / 60$ visual acuity.

Risk indicators for endophthalmitis - main findings

Multiple logistic regression showed that the occurrence of "capsule rupture and vitreous loss" during the operation had an eightfold higher risk of endophthalmitis (odds ratio 7.9, (95\% CI 3.5 to 17.9 ) compared with the absence of this event during surgery.

Risk indicators for retinal detachment or tear-main findings

"Capsule rupture and vitreous loss" during the operation increased the risk of retinal detachment or tear within 3 months of cataract extraction 10-fold (odds ration 10.3, 95\% CI 4.4 to 23.9 ). Serious co-existing ocular conditions were also observed to be associated with a risk of retinal detachment or tear within 3 months of surgery (odds ratio 2.3) but this was of borderline significance (95\% CI 1.03 to $5.1)$.

\section{Discussion}

National estimates for the clinical outcomes of cataract surgery have been provided by this large dataset. In doing so we favoured a methodological approach which took the key stages of recovery for assessment of outcomes rather than a fixed calendar time of follow up.

We have shown that good visual outcomes are achieved nationally for most cataract patients particularly in patients without ocular comorbidity and in the relatively "young" elderly. At the very poor outcome end of the spectrum $1 \%$ of patients without ocular comorbidity achieved visual acuity less than 6/60 at discharge from postoperative hospital follow up. While these findings represent the "national average" for present performance, the representatives of the ophthalmological community must decide if this can be improved upon. 
Given that almost $80 \%$ of the patients are 70 years of age and over, ${ }^{2}$ and that about $40 \%$ of all patients have ocular comorbidity, our findings on these two factors are offered here to the clinical and scientific community for consideration at national and local level:

- Older age itself was associated with poor visual outcome after adjusting for presence of age related co-existing eye disorders such as age related macular disease

- Ocular comorbidity, diabetes, or stroke were significant risk factors for poor clinical outcome (visual acuity and complications within 48 hours of surgery), after adjusting for the confounding effect of age and other factors in the model shown in Table 1.

This study has demonstrated a definitive strong relation between capsule rupture and vitreous loss and the risk of endophthalmitis, and of retinal detachment or tear within 3 months of cataract surgery.

While it is unlikely that a study of this size can be repeated more than every 10 years, it is possible for smaller in-depth studies to take forward some of the issues raised. At least three important issues arise in relation to outcome of cataract surgery: timing of assessment of outcome, ongoing research into vision and aging, and the need for further study comparing outcomes in specific comorbid groups.

This work was supported by a grant from the NHSE, Department of Health, England.

The authors wish to thank the steering group members from the Royal College of Nursing, the College of Optometrists, and the Royal College of Ophthalmologists. Thanks are due also to Mr Tony Moore, Professor Andrew Elkington, and the staff of the Royal College of Ophthalmologists for their advice and support and to Dr Andrew Burnett of the NHSE, Department of Health, England.

The authors particularly want to thank all those clinical and audit personnel within the UK who diligently collected data for this work from the following centres:

Addenbrooke's Hospital, Hinchingbrooke Hospital, Ipswich Hospital NHS Trust, James Paget Hospital NHS Trust, Luton and Dunstable NHS Trust, Prince Charles Eye Unit Edward VII Hospital, Royal Berkshire Hospital, Stoke Mandeville Hos- pital, West Norwich Hospital, West Suffolk Hospital, Bedford General Hospital, Barnet General Hospital, Royal Free Hospial, University College Hospital, Central Middlesex Hospital, Charing Cross Hospital, Essex Rivers Healthcare Trust, Hillingdon Hospital, Moorfields Eye Hospital, Princess Alexandra Hospital NHS Trust, Queen Elizabeth II Hospital, Western Eye Hospital, Chelsea and Westminster Hospital, Arrowe Park and Wirral Hospital, Royal Bolton Hospitals NHS Trust, Royal Lancaster Infirmary Morecambe Bay Hospitals NHS Trust, Leighton Hospital, Royal Albert Edward Infirmary, Royal Oldham Hospital, Southport and Formby District General Hospital, Victoria Hospital, Warrington Hospital NHS Trust, Drayton House Clinic, Royal Informary, Blackburn, Burnley General Hospital, St Helen's Hospital, West Cumberland Hospital, Bradford Royal Infirmary, Cumberland Infirmary, Darlington Memorial Hospital, Harrogate District Hospital H, Darlington Memorial Hospital, Harrogate District Hospital Healthcare Trust, Huddersfield Royal Infirmary, Hull Royal Infirmary, Leeds General Infirmary, North Riding Infirmary, Pinderfields General Hospital, Royal Halifax Infirmary, Royal Victoria Infirmary, Scarborough Hospital, Sunderland Eye Infirmary, York istrict Hospital, North Devon District Hospital, North Hampshire Hospital, Princess Margaret Hospital, Queen Alexandra Hospital, Royal Hampshire County Hospital, Royal United Hospital, Royal Bournemouth and Christchurch Hospital NHS Trust, Southampton General Hospital, Torbay Hospital, Royal Devon and Exeter Hospital, St Mary's Hospital, East Surrey Hospital, Kent and Canterbury Hospital, Kent County Ophthalmic and Aural Hospital, Kent and Sussex Hospital, King's College Hospital, Queen Mary's Hospital NHS Trust, West Sussex Eye Unit Worthing Hospital, Chesterfield and North Derbyshire Royal Hospital NHS Trust, Derbyshire Royal Infirmary, King's Mill Centre for Healthcare Services NHS Trust, Leicester Royal Infirmary NHS Trust, Lincoln County Hospital, Diana Princess of Wales Hospital NHS Trust, Scunthorpe General Hospital, Alexandra Healthcare NHS Trust, Birmingeral Hospital, Alexandra Healthcare NHS rust, Birmingham and Midlands Eye Centre City Hospital NHS Trust, Selly Oak University Hospital, Birmingham Heartlands Hospital, Guest Hospital, Sandwell General Hospital, ton and Midland Counties Eye Infirmary, Worcester Royal Infirmary NHS Trust, Royal Group of Hospitals Belfast, Aberdeen Royal Infirmary, Ninewells Hospital, Princess Alexandra Eye Pavillion, Queen Margaret Hospital NHS Trust, Royal Alexandra Hospital NHS Trust, Southern General Hospital NHS Trust, West Glasgow Hospitals University NHS Trust, Stobhill Hospital NHS Trust, Stirling Royal Infirmary, Stonehouse Hospital, St John's Hospital, East Glamorgan General Hospital, Prince Charles Hospital, H.M. Stanley Hospital, Wrexham Maelor Hospital, Bronglais General Hospital.

1 McCollum A, Mordue A, Foy C, et al. Assessing the need for cataract surgery. Health Care Needs Division, Northern Regional Health Authority, 1991

2 Desai P, Reidy A, Minassian DC. Profile of patients presenting for cataract surgery in the UK: national data collection. Br f Ophthalmol 1999;83:893-6.

3 Interim Report 1. National cataract survey. Leeds: Department of Health, NHSE, 1997.

4 Kleinbaum DG, Kupper LL, Morgensten H. Epidemiologic research: principles and quantitative methods. New York: Van research: principles and quan
Nostrand Reinhold, 1982. 